\title{
Advance application of geospatial technology for fisheries perspective in Tarai region of Himalayan state of Uttarakhand
}

\author{
Nandkishor A. Ingole ${ }^{1} \cdot$ R. N. Ram ${ }^{1} \cdot$ Rajeev Ranjan ${ }^{2}$ Anil Kumar Shankhwar ${ }^{3}$
}

Received: 7 April 2015/Accepted: 23 July 2015/Published online: 25 August 2015

(C) Springer International Publishing 2015

\begin{abstract}
Remote sensing and geographic information systems (GIS) play a key role in all geospatial aspects of the assessment and management of water resources for inland fisheries and aquaculture. Lake, wetland, and reservoirs are some of the important inland water resources for potential fish production and help improve the rural economy on large scale. Fisheries development perspective reservoirs of the Tarai region are Naitaal, Tumaria, Haripura, Baur, Baigul, Dhaura, Nanaksagar, and Sardasagar, which are located at $28^{\circ} 25^{\prime}-$ $29^{\circ} 55^{\prime} \mathrm{N}$ latitude and $78^{\circ} 18^{\prime}-79^{\circ} 55^{\prime} \mathrm{E}$ longitude. Waterresource assessment such as spread area, water quality, nutrient analysis, chlorophyll content, and other physico-chemica properties may be done through the mapping. Hence, remote sensing and GIS software and images like Landsat-ETM+, Landsat- 8 and other multi spectral images utilization at short time frame for potential fishing zone identification, rate of sedimentation, geomorphological changes such as land cover, erosion and accretion in reservoirs as well. Thus it will help in decision making and blueprint preparation for sustainable water resource management at a cost-effective rate. The current review emphasizes the potential of high-resolution satellite images for mapping and analysis of water resources at Tarai region of Uttarakhand.
\end{abstract}

Anil Kumar Shankhwar

oxeegen@gmail.com

1 Department of Fishery Biology, G.B. Pant University of Agriculture and Technology, Pantnagar, Uttarakhand 263 145, India

2 Department of Agrometeorology, G.B. Pant University of Agriculture and Technology, Pantnagar, Uttarakhand 263 145, India

3 Department of Environmental Science, G.B. Pant University of Agriculture and Technology, Pantnagar, Uttarakhand 263 145, India
Keywords Remote sensing · GIS - Reservoirs - Satellite images - Water resources management

\section{Introduction}

Water is an essential, natural, inexorable, life-sustaining commodity for human beings in day to day life. But nowadays it is becoming inaccessible due to increasing water pollution as a consequence of accelerated industrial and urban growth (Shankhwar and Srivastava 2015). The problem of water pollution is one such havoc that has taken the attention of scientists and social activists all round the globe (Mishra et al. 2015). These days' technology involved in wastewater treatment uses innovative, efficient, and advanced methods. However, these methods need to be economically viable, especially in the rural part of India, e.g. Uttarakhand, to support wastewater management and reuses. Freshwater scarcity is a worldwide challenge for sustainable development. Human interference, inadequate freshwater supply, and inappropriate management are the major causes that lead to more pollutant load to water body (Shankhwar et al. 2015) and ultimately diminish the water quality. Hence, remote sensing and GIS are decision supporting technical tools that provide spatial and temporal variations in number of water bodies and water spread area (Chowdhury et al. 2009). Thus the mapping of fisheries resources would provide pithy information for socioeconomic perspective of sustainable water management with economic returns. Since beginning, GIS and GPS technology facilitates to access natural resource data of remote area for their mapping and management.

Remote sensing technology facilitates the advantage of spatial, spectral, and temporal availability of data covering large and inaccessible areas within a short time. Hence, it has emerged as a powerful tool for assessment, monitoring, 
and management of water bodies. GIS is a computer-based information system used to digitally represent and analyse the geographic features present on the earth surface and the events (non-spatial attributes linked to the geography under study) that are taking place on it (Jenness et al. 2007).

Images from Earth-Observation satellites have been used to survey surface water resources, since the early days of the Landsat programme. Several investigators like Best and Moore (1979) also showed that the reliable regional statistical models could be developed to estimate small water body volumes from areas determined with Landsat MSS images. Eckhaedr and Lirke (1988) surveyed water bodies in Colorado with Landsat MSS and Satellite Pour l'Observation de la Terre (SPOT) High Resolution Visible (HRV) images detecting ponds as small as 0.5 and 0.1 ha, respectively.

Furthermore, several scientists preferred the remote sensing and GIS tools for water resources and fisheries management. De Silva et al. (2001) used GIS to integrate fishery yield data, fishing intensity, and landing size together with selected limnological data, such as conductivity and chlorophyll for nine tropical reservoirs in Sri Lanka. They established relations of fish yield to environmental parameters. Further, the National Remote Sensing Centre (2003) observed sedimentation rate per year for different reservoirs in India as Kuttiyadi (0.12\%) during 1989-1995; Bargi $(0.07 \%)$ during 1990-2000; Sriram Sagar (1.0\%) during 1970-2002; Tawa (0.7 \%) during 1975-1996; Bhakara (0.14 \%) 1958-1996; Pong (0.22 \%) during 1974-1996; Ujjani (1.18 \%) during 1976-1992; Nathsagar (0.48 \%) during 1976-1992; and Tunbhagra (0.59\%) during 1953-1995. Identifying and mapping Potential Fishing Zones (PFZ), coastal zone management, monitoring of aquaculture activities, ocean colour analysis and phytoplankton concentration, biodiversity management, monitoring of water pollution, mapping, and management of natural resources (marine protected areas, water bodies, coral reefs, sea grasses, mangroves), change detection and monitoring (reservoir, estuaries, coastal areas) are some of the applications of remote sensing and GIS in fisheries (Gaarf et al. 2003; Ghatge 2008; Hui et al. 2008; Salgaonkar 2010).

The reservoirs are mainly used for irrigation, hydropower generation, and fish production. The average fish production rate in the reservoirs of Uttarakhand is about $25 \mathrm{~kg} / \mathrm{ha}$ which can be increased up to $200 \mathrm{~kg} / \mathrm{ha}$ (Sharma et al. 2005) by upgrading the ecosystem management. Economic concern for conservation of water body can be managed through the adoption of fishery that enables to sustain the biological diversity and perpetuation.

Therefore, in the present study an attempt has been made from a fisheries perspective of various water bodies of Tarai region in the Himalayan foothill of Uttarakhand state through remote sensing and GIS techniques.

\section{Over view of the study area}

Uttarakhand, the newly carved hill state of India, has enormous natural inland water resources in the form of rivers $(2700 \mathrm{~km})$, reservoir (24,200 ha), lakes (297 ha), ponds ( $>2000 \mathrm{ha})$, etc. Tarai region has highly productive water bodies due to thermostratification and also good soil status of catchment area in Uttarakhand and some parts of Uttar Pradesh (Sugunan 2011). The man-made lakes (reservoirs) in the Uttarakhand have been constructed in the post-independence period and are located at $28^{\circ} 25^{\prime}-29^{\circ} 55^{\prime} \mathrm{N}$ latitude and $78^{\circ} 18^{\prime}-79^{\circ} 55^{\prime} \mathrm{E}$ longitude. A sample of subset images of the important reservoirs of the Tarai region has been depicted in Fig. 1. They have slow valley bottoms below $609 \mathrm{msl}$ and have a hot and moist tropical climate, which is influenced by southwest monsoon.

\section{Satellite images}

Landsat enhanced thematic mapper plus (ETM+) images (with spatial resolution of $30 \mathrm{~m}$ ) as well as the original imagery can be viewed online or downloaded (Fig. 2). These images are freely available for download from the USGS Glovis website (http://glovis.usgs.gov) in the "GeoTIFF plus Metadata" format so this will not be an issue of using these images and even the georeferenced images are enable to be easily read by GIS software. Remote sensing data (Landsat ETM+ images) were used for the assessment of water resources in the Tarai region.

\section{Softwares used}

\section{Image processing software}

The ERDAS IMAGINE ${ }^{\circledR}$ is a large and easy-to-use selection of image processing tools; it both simplifies and streamlines the workflow. Recent geo-coded data can be used to demarcate the ground control points (GCPs) using global positioning system (GPS). Digital data or raw image can be processed using various software like ERDAS IMAGINE 8.6, 8.7, 9.0 versions, ENVI-4.4, 4.7, 4.8 versions, TNT, Ilwis, etc. These data can be geo-rectified with the help of toposheets or image to image rectification. Image rectification and restoration are necessary for removing noise from the image.

Subsets of different water bodies such as lakes, reservoirs, rivers, and ponds can be prepared for the study. Subsets require geo-morphological parameters such as area, perimeter of the water bodies, high chlorophyll concentration, soil erosion and accretion, and suitable site for aquaculture through supervised and unsupervised classification technique and region growing tool in the software. 
Fig. 1 Geographical location of the study area (Tarai region)

Fig. 2 A sample of LANDSAT-ETM+ image of 21st October, 2010
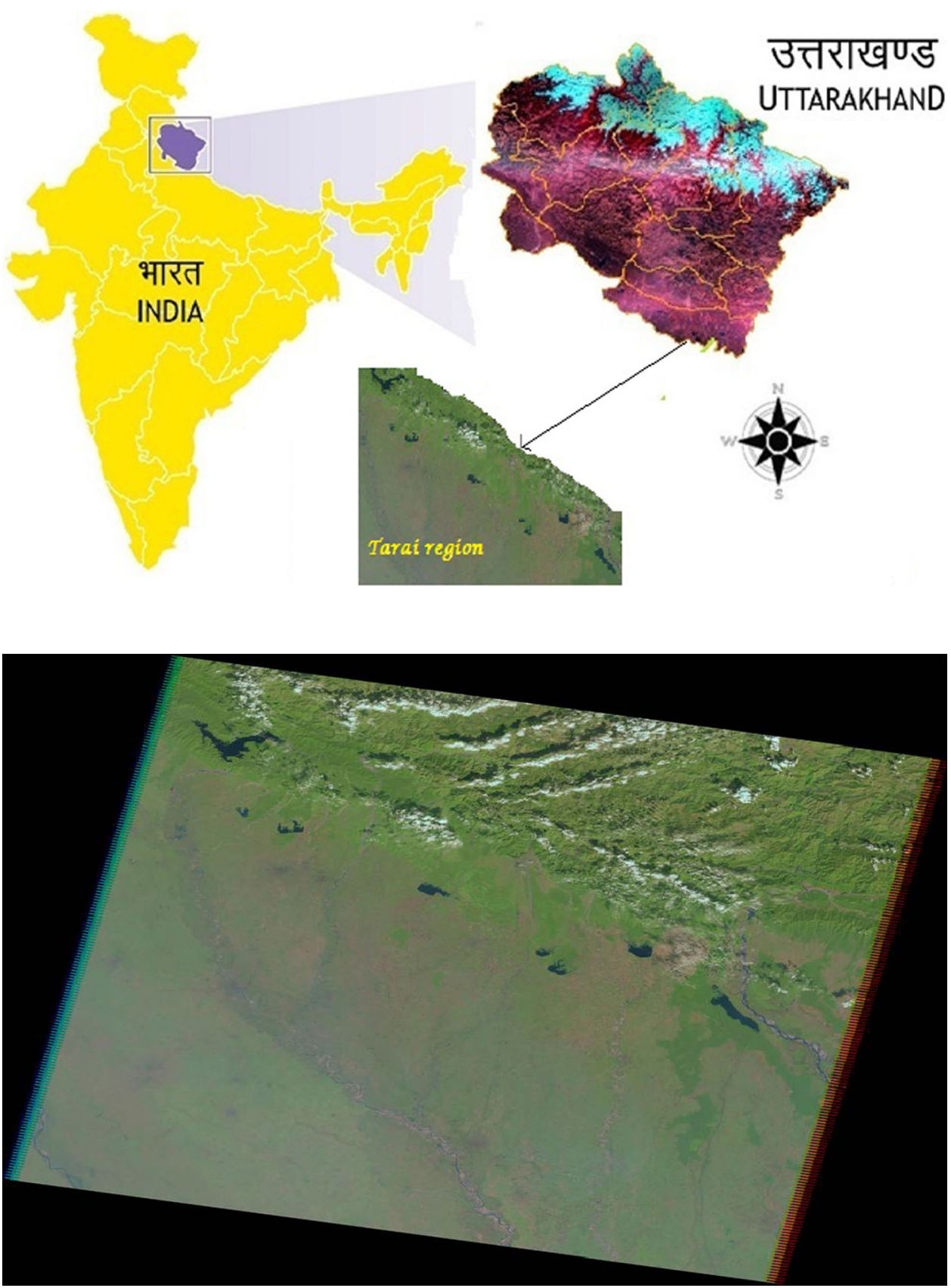

\section{GIS software}

The ArcGIS is worldwide popular desktop mapping and GIS software developed by Environmental Systems Research Institute (ESRI). ArcGIS has great visualisation, query, analysis and integration capabilities along with the ability to create and edit geographic data. Creation of thematic maps and adding data to them is made easy by ArcGIS. Also reports, graphs, etc. can be prepared and displayed instantly from existing databases using the ArcGIS tools.

\section{Water resources in Tarai region}

The man-made lakes and reservoirs in the Uttarakhand have been main water resources for fisheries enhancement and socio-economical development of its surrounding villages. The satellite imagery showing important water resources (reservoirs, river and lake) of Tarai region is been depicted in Fig. 3. The important reservoirs of the Tarai region are Naitaal, Tumaria, Haripura, Baur, Baigul, Dhaura, Nanaksagar, and Sardasagar. All reservoirs have slow valley bottoms, mostly below $609 \mathrm{~m} \mathrm{msl}$, and have a 
hot and moist tropical climate, which is influenced by southwest monsoon. The soil of the area is generally composed of silty and clayey loam with or without gravels and are rich in nutrients.

The following works have applied the remote sensing technique for study of reservoirs in Tarai region.

Nayak et al. (2010) studied on different reservoirs in Tarai region. They used multi-dated satellite images of IRS-P6 LISS III for the year 2004 of the estimated water spread area (WSA) in hector and perimeter (P) in kilometre of reservoirs such as Tumaria (WSA-1604.0; P-57.2), Baur (WSA-1257.6; P-21.7), Haripura (WSA-883.0; P-16.4),
Dhaura (WSA-1350.0; P-31.6), Baigul (WSA-1677.8; P-59.3), Nanak Sagar (WSA-1760.3; P-39.3), Sarda Sagar (WSA-4856.0; P-63.2), and Ramganga Sagar (WSA4486.4; P-204.4).

Ingole (2012) studied on Nanak Sagar reservoir using multi-date remote sensing data (IRS-1C LISS III) which provided the information on the water spread area of the reservoir (Fig. 4), which was used for computing the sedimentation rate. The revised capacity of the reservoir between maximum and minimum levels was computed using the Trapezoidal formula. The loss in reservoir capacity due to sediment deposition for the period of

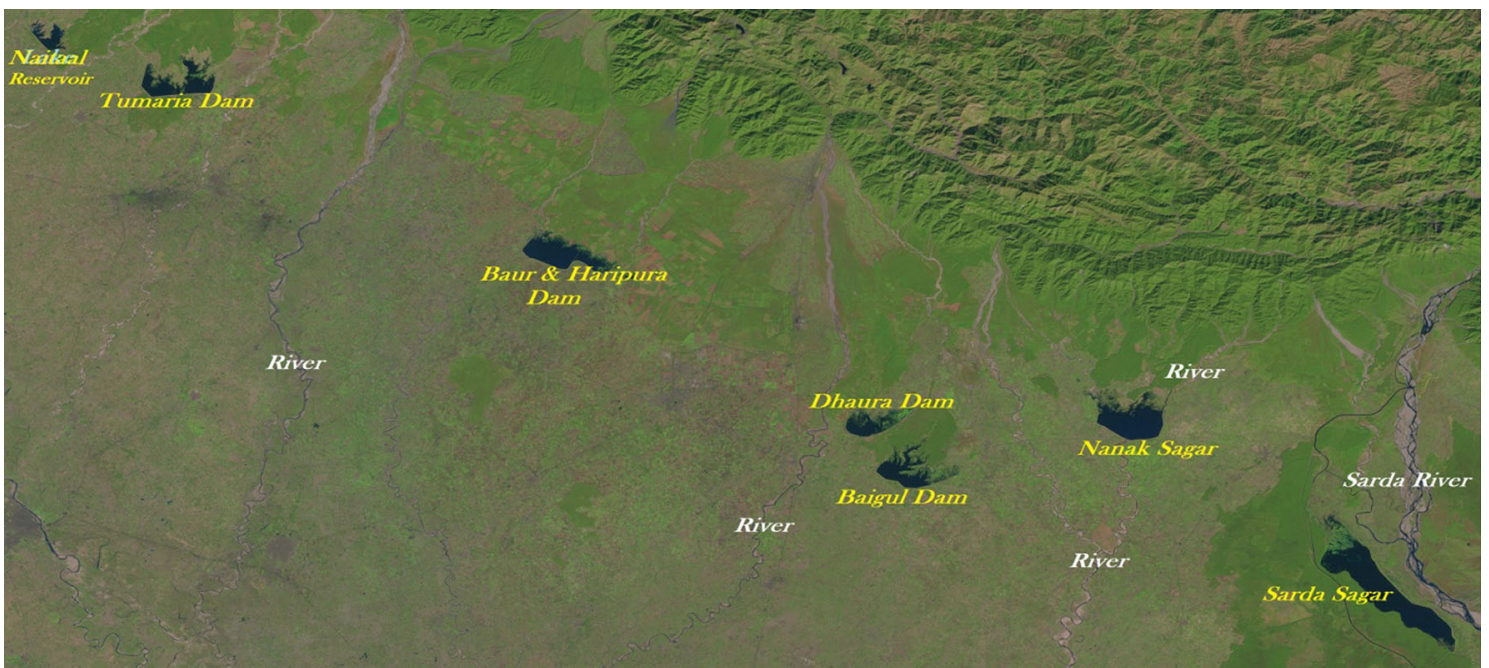

Fig. 3 Satellite imagery showing important water resources (reservoirs) of Tarai region

Fig. 4 Satellite derived water spread for various overpass dates (Source Ingole 2012)

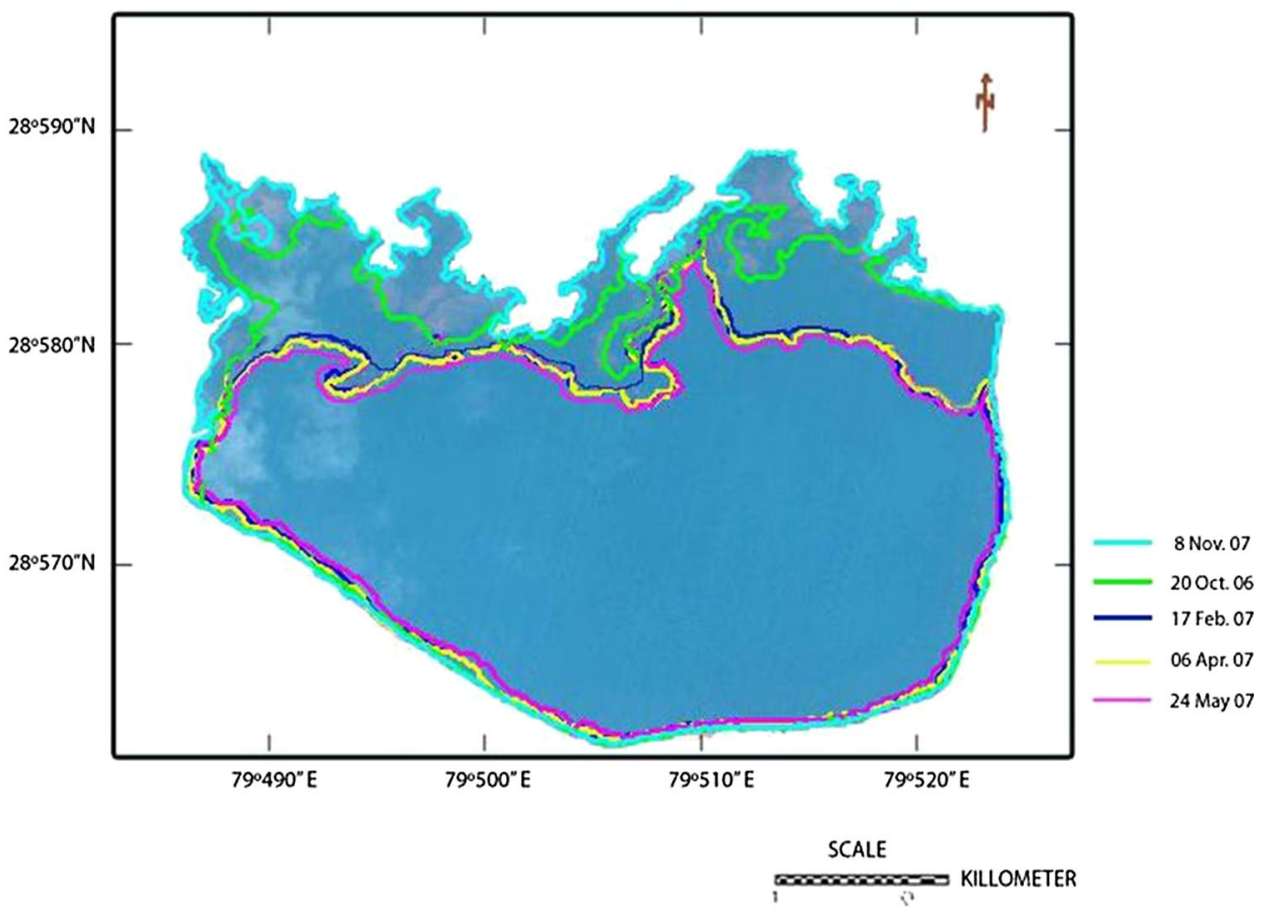


Fig. 5 Productive zone of

Sarda Sagar reservoir (Source Kumar 2008)

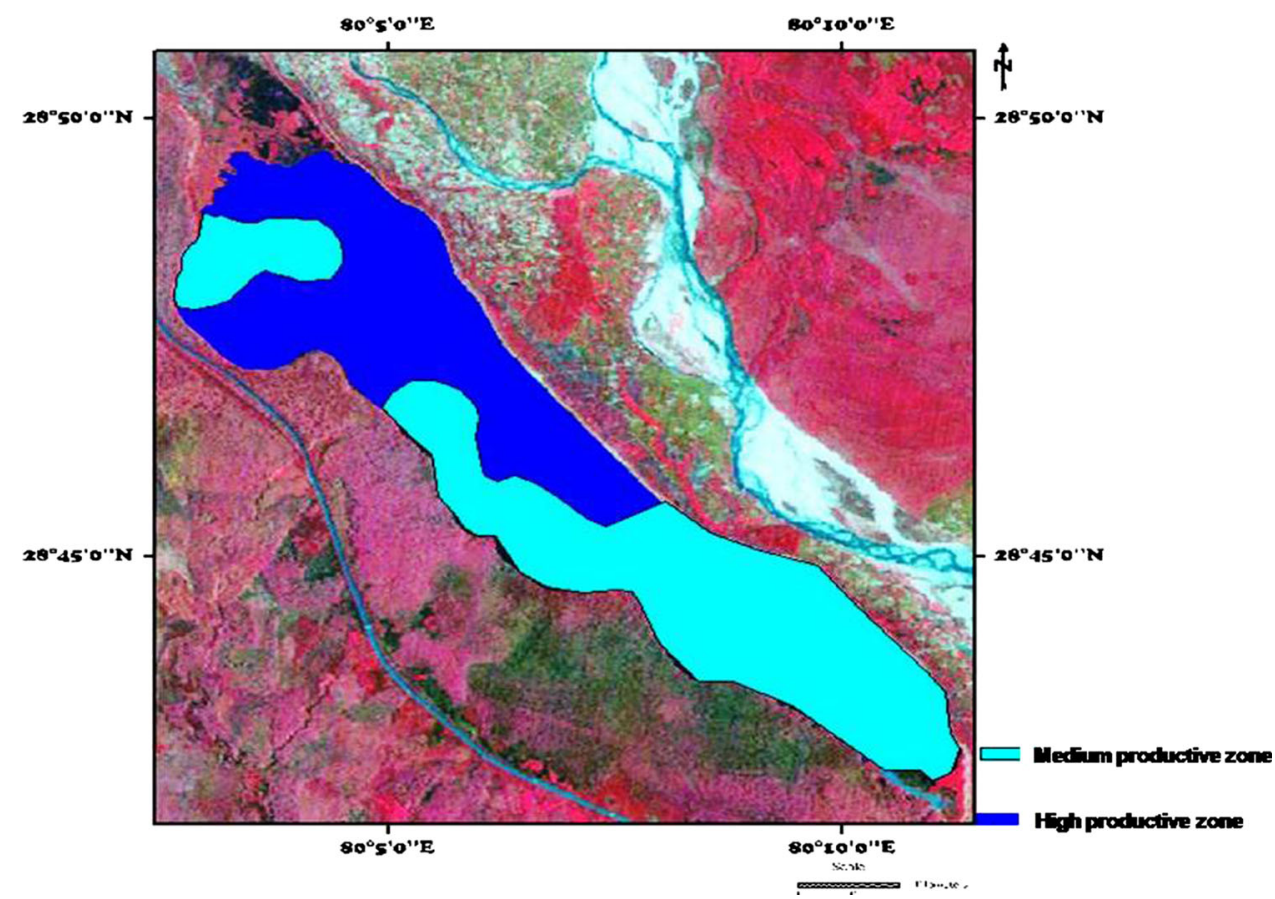

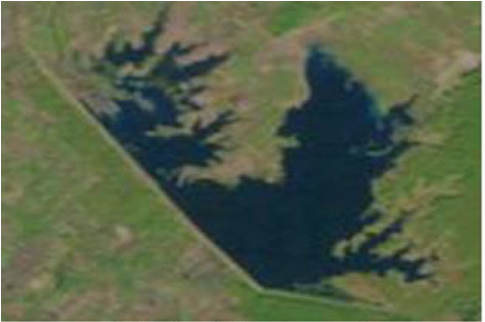

Naitaal Reservoir

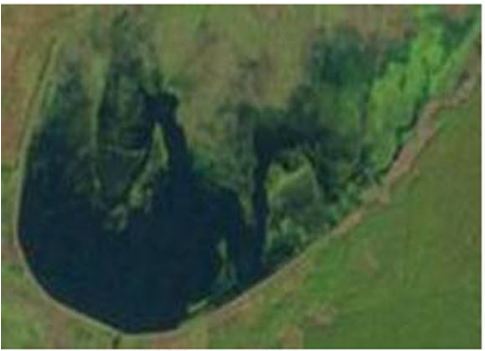

Dhaura Dam

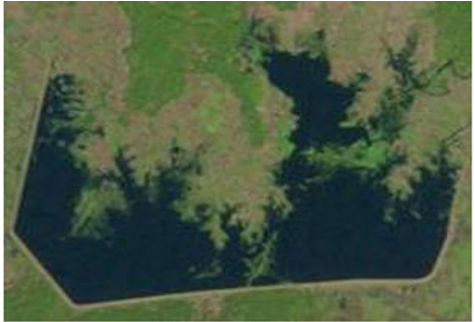

TumariaDam

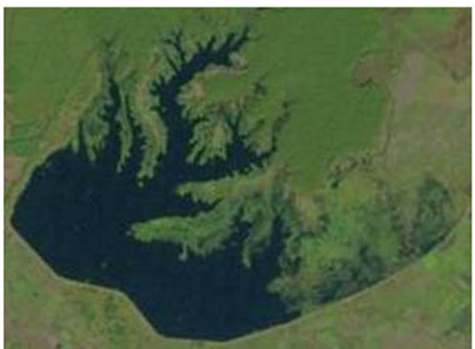

BaigulDam

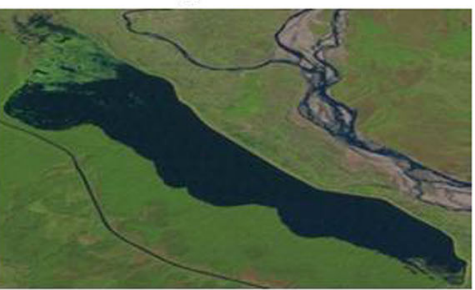

Sarda Sagar

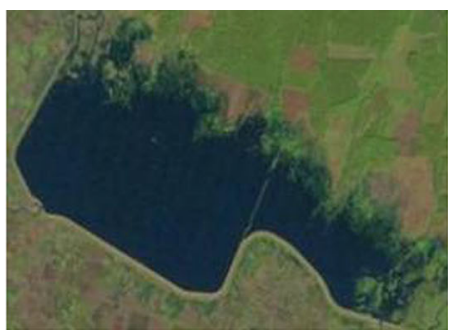

Baur \& Haripura Dam

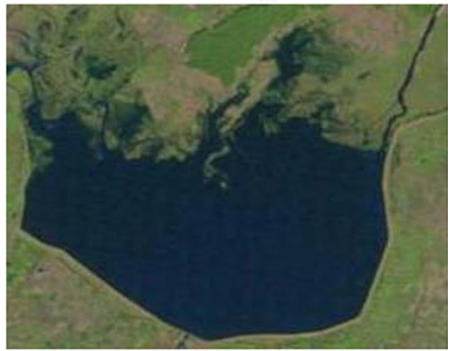

Nanak Sagar

Fig. 6 Subset images of the important reservoirs in Tarai region of Uttarakhand 
45 years $(1962-2007)$ was determined to be $56.19 \mathrm{~mm}^{3}$ $(26.78 \%)$, which gives an average sedimentation rate of $1.25 \mathrm{~mm}^{3}(0.59 \%)$ per year (Ingole et al. 2015). He evaluated the sedimentation and turbidity which are significant contributors to the decline of aquatic organisms. Direct effects at each trophic level are mortality, reduced physiological function, and avoidance; however, decreases in available food at trophic levels also results in depressed rates of growth, reproduction, and recruitment (Argent and Flebbe 1999; Berkman and Rabeni 1987; Ryan 1991; Waters 1995; Ingole et al. 2014).

Kumar (2008) studied on Sarda Sagar reservoir using multi-date remote sensing data (IRS-1C LISS III) and estimated water spread area and sedimentation rate/year $(0.26 \%)$ during 1962-2007. Also a modelling was carried out based on criteria of optimum range of all physicochemical properties of the reservoir water to obtain the high productive zone of Sarda Sagar (Fig. 5). Based on the survey and model, the production potential was calculated as $65 \mathrm{~kg} / \mathrm{ha}$ in the Sarda Sagar.

Likewise, we can assess the water spread area, water quality (physical-chemical analysis and nutrient analysis; chlorophylls concentration), mapping of suitable area for fishing (Fishing Potential Zone), rate of sedimentation, geomorphological changes (land cover, erosion and accretion) (Kumar et al. 2001) to help the water resources (Rivers, Lakes, Reservoirs), and their fisheries management in Tarai region of Uttrakhand. A sample of subset images of all the reservoirs that come under Tarai region of Uttarakhand is depicted in Fig. 6.

\section{Conclusion}

Advanced technology, remote sensing, and GIS can be used successfully to perform water resources assessment in the Tarai reservoirs using MSS satellite images, where the surface reservoir areacan be a good means to assess the water storage in the reservoir and calculate its life span. Using such technology is helpful to prepare an inventory for a suitable site of cage and pen culture. Explicitly, this paper concludes the key role of that geospatial technology for culture and capture based fisheries and in enhancing the fish production with economic returns of reservoirs as well.

\section{References}

Argent DG, Flebbe PA (1999) Fine sediment effects on brook trout eggs in laboratory streams. Fish Res 39:253-262

Berkman HE, Rabeni CF (1987) Effect of siltation on stream fish communities. Environ Biol Fishes 18:285-294
Best RG, Moore DG (1979) Landsat interpretation of prairie lakes and wetlands of Eastern South Dakota. Satellite hydrology. In: Proceedings of the 5th Willian T. Pecora memorial symposium on remote sensing, Sioux Falls, South Dakota U.S.A. August 1979, American Water Resources Association, Bethesda, MD, pp 499-506

Chowdhury A, Jha MK, Chowdary VM, Mal BC (2009) Integrated remote sensing and GIS based approach for assessing groundwater potential in West Medinipur district, West Bengal, India. Int J Remote Sens 30(1):231-250

De Silva SS, Amarasinghe US, Nissanka C, Wijesooriya WADD, Fernando MJJ (2001) Use of geographical information systems as a tool for predicting fish yield in tropical reservoirs: case study on Sri Lankan reservoirs. Fish Manag Ecol 8:47-60

Eckhaedr DW, Lirke DW (1988) Estimation of reservoir surface areas using satellite imagery. Upper Gunison Basin, Colorado. Conference on water data for water resources management, Tucson, Arizona, U.S.A. August 1988, American Water Resources Association, Bethesda, MD, pp 691-702

Gaarf GD, Martin F, Manjarezz JA, Jenness J (2003) Geographic information systems in fisheries management. FAO fisheries technical paper. 449:1

Ghatge SS (2008) Fisheries GIS for Greater Mumbai Region. M.F.Sc Thesis. Central Institute of Fisheries education, Mumbai

Hui F, Xu B, Huang H, Yu Q, Gong P (2008) Modelling spatialtemporal change of Poyang Lake using multi-temporal Landsat imagery. Int J Remote Sens 29(20):5767-5784

Ingole NA (2012) Assessment of sedimentation status using Remote Sensing data and its impact on ichthyofaunal diversity in Nanak Sagar reservoir of Tarai region of Uttarakhand, M.F.Sc. Thesis, G.B. Pant University of Agri. and Tech, Uttarakhand (India)

Ingole NA, Ram RN, Kumar P (2014) Study of morphometrical changes and suspended sediments in Nanak Sagar reservoir of Uttarakhand, India, using remote sensing data \& its impact on Ichthyofaunal diversity. Eco Env Cons 20(Suppl):S373-S379

Ingole NA, Ram RN, Kumar P (2015) Assessment of sedimentation in Nanak Sagar reservoir of Uttarakhand, India: using remote sensing technique. J Env Bio Sci 29(1):17-21

Jenness J, Dooley J, Aguilar MJ, Riva C (2007) African Water Resource Database. GIS-based tools for inland aquatic resource management. 1. Concepts and application case studies. CIFA technical paper. no. 33, part 1. Rome, FAO

Kumar P (2008) Spatial database on fish and fisheries resources of Sarda Sagar reservoir, Tarai region of Uttarakhand and UP, India. PhD Thesis M.J.P. Rohilkhand University, Bareilly, UP

Kumar P, Meenakumari B, Bandyopadhyay JK (2001) Geomorphological changes in Sagar Island: a remote sensing study. Reverine and Reservoir fisheries of India, Society of Fisheries Technologist (India)

Mishra T, Ramola S, Shankhwar AK, Rabha AK, Srivastava RK (2015) Pulp and paper mill effluent treatment by hybrid anaerobic upflow fixed-bed bioreactor combined with slow sand filter. Desalin Water Treat. doi:10.1080/19443994.2015.1039596

Nayak KA, Kumar P, Singh NO, Haldar RS, Ali S, Mahanta PC (2010) Geoinformatics application in assessment of fishery resources of Uttarakahnd. Directorate of Coldwater Fisheries Research, Bhimtal (ICAR) Bulletin No. 17

NRSC (National Remote Sensing Centre) (2003) Reservoir sedimentation assessment using satellite remote sensing techniqueexpertise \& experience of NRSA. Water Recourse Division, NRSA (Dept. of Space), Hyderabad

Ryan PA (1991) Environmental effects of sediment on New Zealand streams: a review. New Zeal. J Mar Freshw Res 25:207-221

Salgaonkar AA (2010) A study of temporo-spatial changes in inland water bodies of Ratnagiri district using Remote Sensing and GIS. Master Thesis CIFE, Mumbai (MH) 
Shankhwar AK, Srivastava RK (2015) Biomass production through grey water fertigation in Eucalyptus hybrid and its economic significance. Environ Prog Sustain Energy 34(1):222-226

Shankhwar AK, Ramola S, Mishra T, Srivastava RK (2015) Grey water pollutant loads in residential colony and its economic management. Renew: Wind Water Sol 2(1):5

Sharma AP, Ram RN, Mistra A (2005) Assessment of fish production potential and development of norms for fisheries management in reservoir of Uttarakhand. Report submitted to Dept. of Fisheries, Govt. of Uttarakhand, 28
Sugunan VV (2011) Reservoir fisheries. In: Trivedi TP (ed) Handbook of fisheries and aquaculture. Directorate of Knowledge Management in Agriculture ICAR, New Delhi, vol 2, pp 238-274

Waters TF (1995) Sediment in sreams: sources, biological effects and controls., American Fisheries Society Monograph 7American Fisheries Society, Bethesda 